\title{
Resíduos de gesso de construção civil: minimização e estudos de lixiviação
}

\section{Construction waste gypsum: minimization and leaching studies}

\author{
Carlos Eduardo Rubio Senes ${ }^{1}$, Cleber Antônio Lindino ${ }^{2}$
}

\begin{abstract}
Resumo
O gesso é um material muito utilizado na construção civil e produz resíduos no seu processo de fabricação e na demolição de obras de construção civil. Esse trabalho buscou alternativas que diminuam a produção de resíduos no processo de fabricação do gesso utilizando aditivos na sua composição, e também procurou avaliar o processo de lixiviação em meio aquoso dos resíduos de gesso produzidos em demolições de construções, devido ao seu possível uso em pisciculturas. Diferentes gessos modificados foram avaliados em vários parâmetros como tempo de cura, aspecto, resistência e alterações morfológicas, sendo que gessos modificados com terra diatomácea apresentaram resultados favoráveis. Resíduos de gesso sem contaminantes e gesso puro foram submetidos a testes de lixiviação em diferentes valores de $\mathrm{pH}$ para avaliar os processos químicos em dois períodos de tempo diferentes. Analisou-se parâmetros como condutividade, turbidez e teor de cálcio nas amostras lixiviadas, verificando que o gesso e seu resíduo influenciam no meio aquoso, principalmente no $\mathrm{pH}$, na condutividade e na turbidez, implicando em alerta no seu uso em tanques de piscicultura.
\end{abstract}

Palavras-chave: Tempo de cura. Resíduo sólido. Aditivos. Lixiviação.

\begin{abstract}
Plaster is a very useful material in construction, but it is responsible for producing waste in the manufacturing process and also the demolition works. This work seeks alternatives that reduce the production of waste in the manufacturing process using plaster additives in their composition and also to assess the damage caused by improper disposal of waste produced in buildings demolition, due to its possible use in fish farms. Different modified plasters were evaluated on various parameters such as cure time, appearance, resistance and morphological changes. The modified plasters with diatomaceous earth show good results. Waste of plaster and pure plaster were submitted to leaching tests at different $\mathrm{pH}$ values to evaluate its behavior in two different periods of time. It was analyzed parameters such as conductivity, turbidity and calcium contents in the leached samples, checking that the plaster and your residue influence the aquatic environment. It was found that $\mathrm{pH}$, conductivity and turbidity are altered when subjected to gypsum concentrations.
\end{abstract}

Keywords: Cure time (Phase). Solid residue. Additives. Leaching.

${ }^{1}$ Graduado em Química Bacharelado, Universidade Estadual do Oeste do Paraná; carlosedu_rs@hotmail.com

2 Docente do Departamento de Química, Universidade Estadual do Oeste do Paraná - Grupo Interdisciplinar de Pesquisas em Fotoquímica e Eletroquímica Ambiental - GIPEFEA; Laboratório de Estudos em Química Analítica Limpa - LEQAL; lindino99@gmail.com 


\section{Introdução}

\section{Gesso}

O gesso é um material cada vez mais utilizado na construção civil e é produzido a partir do aquecimento da gipsita, um mineral abundante na natureza, constituído principalmente por sulfato de cálcio di-hidratado $\left(\mathrm{CaSO}_{4} \cdot 2 \mathrm{H}_{2} \mathrm{O}\right)$. Porém, uma das características da gipsita é ser facilmente convertida em sulfato hemidratado de cálcio $\left(\mathrm{CaSO}_{4} \cdot{ }^{1} / 2 \mathrm{H}_{2} \mathrm{O}\right)$, no processo de calcinação (BALTAR, 2005).

O mineral di-hidratado tem grande utilização na agricultura e na indústria do cimento. Já o sulfato hemidratado de cálcio pode ser facilmente moldado antes de endurecer, sendo assim utilizado para a elaboração de peças para a construção civil, material ortopédico, material dental, entre outros (BALTAR, 2005).

A gipsita tem a propriedade de perder e recuperar a água de cristalização. No processo de calcinação, a uma temperatura entre $125^{\circ} \mathrm{C}$ e $180{ }^{\circ} \mathrm{C}$, a gipsita perde parte da água de cristalização e assume a forma de hemidrato (gesso), de acordo com a reação 1 (BALTAR, 2005).

\section{$\mathrm{CaSO}_{4} \cdot 2 \mathrm{H}_{2} \mathrm{O} \longrightarrow \mathrm{CaSO}_{4} \cdot 1 / 2 \mathrm{H}_{2} \mathrm{O}+1 \frac{1 / 2}{2} \mathrm{H}_{2} \mathrm{O}$ (Gipsita) \\ (Gesso)}

A desidratação total da gipsita ocorre em temperaturas acima de $180^{\circ} \mathrm{C}$ e resulta nas diferentes formas de anidrita (CaSO ) (CALVO, 2003):

entre 180 e $250{ }^{\circ} \mathrm{C}$ forma-se a anidrita III, também conhecida como anidrita ativa, um produto solúvel, instável e hidrofílico, que pode absorver umidade atmosférica e passar à forma de hemidrato; na temperatura entre 300 e $700{ }^{\circ} \mathrm{C}$ obtém-se a anidrita II, um produto totalmente desidratado, insolúvel, com natureza mineralógica semelhante à anidrita natural; entre as temperaturas de 700 e $900{ }^{\circ} \mathrm{C}$ forma-se um produto inerte, sem aplicação industrial; a partir dos $900{ }^{\circ} \mathrm{C}$ ocorre a dissociação do sulfato de cálcio com formação do $\mathrm{CaO}$ livre.
De acordo com a Associação Brasileira de Normas Técnicas, o gesso para a construção civil deve obedecer às especificações para as propriedades físicas e mecânicas e outras exigências de acordo com as normas NBR-13207, NBR-12127, NBR-12128 e NBR-12129 (BRASIL, 1991a; BRASIL, 1991b; BRASIL, 1991c; BRASIL, 1994).

A preparação do gesso para moldagem de peças envolve a adição de água que dependente da microestrutura do gesso. Cristais bem formados requerem menor quantidade de água, enquanto que aqueles mal formados necessitam de mais água. Durante o endurecimento da pasta, o aquecimento provoca a evaporação da água excedente (comparada com a quantidade estequiométrica necessária). Quanto maior a porosidade do gesso, menor a sua resistência mecânica. Quanto maior a quantidade de água para a formação da pasta maior é a porosidade formada e, consequentemente, menor a resistência mecânica do material. Entretanto, a redução da quantidade de água fica condicionada à obtenção de moldes. Pouca água reduz a fluidez da pasta e a possibilidade de se obter moldes mais precisos, embora o material resultante passe a apresentar uma maior resistência (BRASIL, 1994), (AVELAR, 2012).

\section{Resíduos de gesso da construção civil}

O gesso utilizado na construção civil pode ser empregado em diversas formas, desde revestimento de paredes e teto, quanto como material utilizado na produção de molduras, placas de forro, entre outros (ASSOCIAÇÃO BRASILEIRA DE DRYWALL - ABD, 2009), (SÁ; PIMENTEL, 2009), (JOHN; CINCOTTO, 2003).

Da mesma forma que os demais resíduos gerados na construção civil, o gesso deve ter atenção especial, visto que uma incorreta destinação do mesmo pode ocasionar problemas ambientais (ABD, 2009), (SÁ; PIMENTEL, 2009), (JOHN, CINCOTTO, 2003). 
De acordo com a resolução do CONAMA $n^{\circ}$ 431/2011, o resíduo de gesso é classificado como pertencente à classe $\mathrm{B}$, ou seja, resíduo reciclável para outras destinações (BRASIL, 2011). Assim, depois de separado de outros resíduos da construção, os resíduos de gesso readquirem as características químicas do mineral de que o gesso foi extraído, a Gipsita, permitindo então que o mesmo possa ser novamente reutilizado (ABD, 2009), (SÁ; PIMENTEL, 2009), (JOHN; CINCOTTO, 2003).

As disposições irregulares resultam, na maioria das vezes, de pequenas obras ou reformas, frequentemente por processos de autoconstrução e que não dispõem de recursos financeiros para contratar uma empresa transportadora de Resíduo de Construção Civil (RCC). Esta situação é fortemente agravada pela atuação de transportadores irregulares, sobretudo dos pequenos veículos coletores com baixa capacidade de deslocamento, dentre os quais se destacam as carroças de tração animal.

De acordo com a Resolução 307 do CONAMA, os resíduos de construção civil como o gesso não poderão ser descartados junto com lixos domiciliares (BRASIL, 2002) e, para isso, em vários municípios brasileiros existem as Áreas de Transbordo e Triagem (ATT), licenciadas pelos órgãos ambientais para receberem resíduos de gesso e também outros materiais (ABD, 2009), (SÁ; PIMENTEL, 2009), (JOHN; CINCOTTO, 2003).

Neste contexto, a diminuição na quantidade de resíduos gerados dos processos de manufatura e instalação de gesso na construção civil é importante para a gestão dos resíduos sólidos nos municípios. Para tanto, estudos envolvendo aditivos para induzir o aumento no tempo de cura ou "tempo de pega" são importantes (BADENS, 1999), (RIBEIRO; MACHADO, 2013), (LIMA, 2013).

Um destes promissores aditivos é a terra diatomácea. A terra diatomácea é originada por frústulas ou carapaças de organismos unicelulares vegetais. É caracterizada por ser um sedimento amorfo com natureza silicosa. Apresenta elevada área superficial específica, baixa densidade e estrutura semelhante a um favo de mel. É um produto natural, estável e não produz resíduos químicos tóxicos, sendo comumente utilizada como filtro, isolante térmico, na agricultura, entre outras utilizações (SILVEIRA, et al., 2011).

Empresas que fabricam placas e artefatos com gesso podem utilizar parte de seus resíduos em seu processo industrial. Este recurso é pouco comum, embora seja viável. Além dos próprios fabricantes, há também a possibilidade de reutilizar este material em outras frentes como, por exemplo, pela indústria cimenteira, na qual o gesso é um ingrediente útil e necessário na fabricação do cimento e como aditivo na produção de sínter em usinas siderúrgicas, e, por último, no setor agrícola, que utiliza o gesso para controlar a acidez do solo e aprimorar suas características, além de ter efeito fertilizante, pois é fonte de cálcio e enxofre (AVELAR, 2012), (ABD, 2009), (SÁ; PIMENTEL, 2009), (SANTOS, et. al., 2014). Outros usos para os resíduos de gesso incluem aditivos para compostagem, forração para animais, absorvente de óleo e secagem de lodo de esgoto (MARVIN, 2000).

Com relação ao uso do gesso ou resíduo de gesso na piscicultura, algumas publicações citam o seu uso como agente para minimizar a turbidez e para diminuição do teor de fosforo no meio aquático (QUEIROZ, 2006), (BOYD, 1979), (ROWAN, 2001), além de estudos para uso no transporte de tambaquis (GOMES, et. al., 2006).

Entre os benefícios da utilização do gesso na piscicultura tem-se citado o aumento dos valores de dureza total da água sem causar alterações na alcalinidade da mesma (PARANÁ, 2001). Cartilhas de recomendação provenientes de órgãos públicos se baseiam em publicações estrangeiras que não refletem o clima tropical e as condições características de solo 
e sedimento das regiões brasileiras, não havendo estudos sistemáticos que mostre o quanto esta prática afeta o ecossistema.

Testes de lixiviação, como os preconizados pela NBR 10.005 e 10.006 (BRASIL, 2004a; Brasil, 2004b), não são realizados na avaliação dos resíduos de gesso de construção civil em aplicações na piscicultura.

Este trabalho avaliou aditivos que possam aumentar o tempo de cura do gesso (diminuindo os desperdícios) e procurou entender o processo de lixiviação dos mesmos em ambientes aquosos para prever alterações que possam influenciar o uso de resíduos de gesso em pisciculturas, incluindo a possível presença de chumbo (FONTANELLA; MISTURA, 2014).

\section{Metodologia}

Todos os reagentes químicos utilizados neste trabalho foram de pureza grau para análise. A água utilizada para o preparo de soluções padrão ou diluições de amostras foi destilada e purificada por osmose reversa (ADAMO, resistência da água de 5 $\mathrm{M} \Omega \mathrm{cm}^{-1}$ a $25^{\circ} \mathrm{C}$ ).

\section{Estudo do tempo de cura}

A partir de moldes para gesso a base de silicone padronizou-se a proporção de $40 \mathrm{~g}$ de gesso com 30 $\mathrm{mL}$ de água $(1,33: 1 \mathrm{~m} / \mathrm{v})$, como material de referência, cronometrando-se o tempo de cura (erro de \pm 1 s) como sendo o momento em que havia o endurecimento do material, dificultando a agitação.

Outras amostras de gesso foram preparadas substituindo-se a água por diferentes soluções salinas na concentração de 1,0 $\mathrm{mol} \mathrm{L}^{-1}$ de sulfato de sódio, sulfato de cálcio, sulfato de alumínio, sulfato de magnésio, sulfato de potássio, citrato de sódio e ácido cítrico. Também se utilizou terra diatomácea na proporção de 1, 2 e $5 \%$ m/m, marca Celaton FW 14, com $8 \mu$ de tamanho de partícula e densidade de $2,33 \mathrm{~g}$ $\mathrm{cm}^{-3}$
Os materiais de gesso obtidos foram analisados por espectrofotometria na região do infravermelho, entre 4000 e $700 \mathrm{~cm}^{-1}$, por refletância total atenuada (ATR), com resolução de $2 \mathrm{~cm}^{-1}$ e 20 varreduras sucessivas em equipamento PerkinElmer. Testes de resistência à compressão foram realizados em uma prensa SPECAC (Figura 1). Também mediu-se a variação de temperatura desde o momento da mistura até o endurecimento da pasta na obtenção do gesso modificado, utilizandose um termômetro digital tipo termopar Incoterm de ponta com resolução de $\pm 0,1{ }^{\circ} \mathrm{C}$. A manufatura dos moldes foi realizada em temperaturas ambientes entre 25,0 e $30,0^{\circ} \mathrm{C}$ e umidade relativa do ar entre 50 a $80 \%$.

A balança analítica utilizada nas pesagens foi da marca BEL MarkM214A, com erro de $\pm 0,001$.

Figura 1: Sistema de compressão dos moldes de gesso.

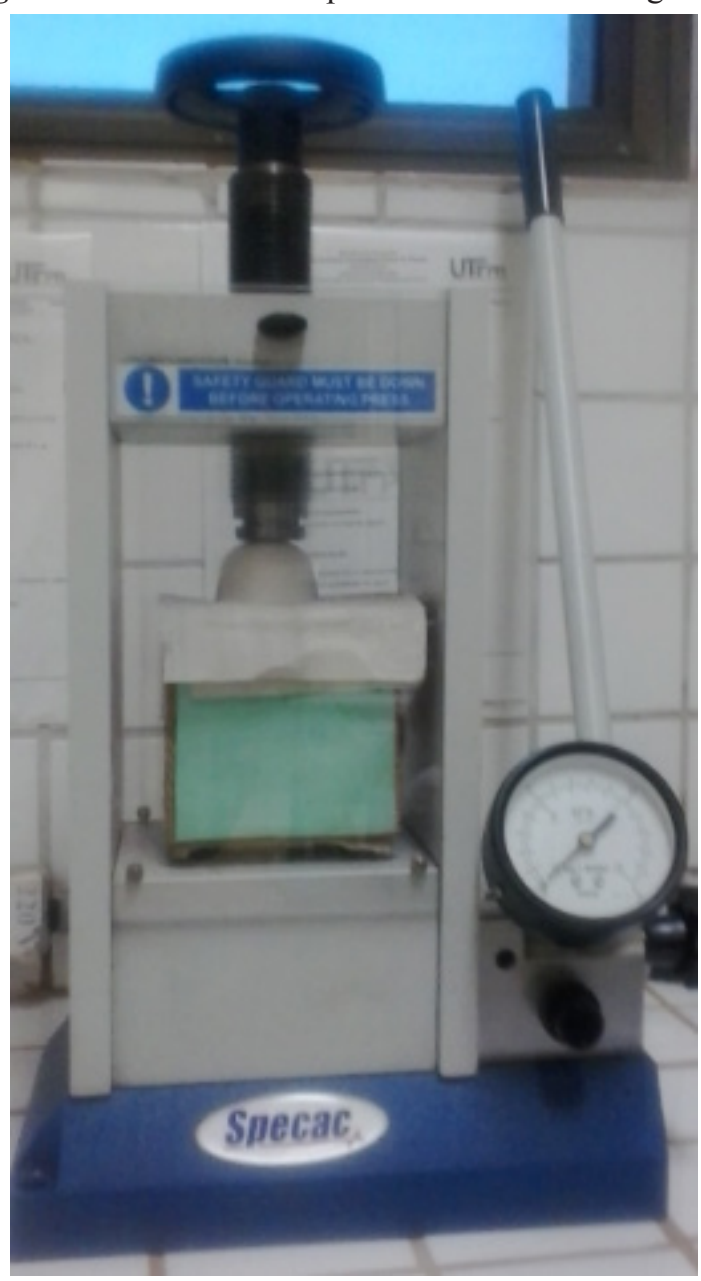

Fonte: os autores. 


\section{Estudo do resíduo do gesso}

Resíduo de acabamento de gesso, limpo de impurezas (papel, óleo, tinta etc) e gesso comercial foram doados por uma empresa de construção civil da cidade de Toledo/PR e realizaram-se testes de avaliação da composição química e processos de tratamento do mesmo.

Amostras de resíduo de gesso previamente pesadas foram colocadas em mufla com temperaturas de 150 a $200{ }^{\circ} \mathrm{C}$ por uma hora. Após o tempo decorrido, as mesmas foram pesadas novamente e calculou-se a quantidade de água de hidratação que foi removida. As amostras também foram submetidas à temperatura de $1100{ }^{\circ} \mathrm{C}$, por uma hora e pesadas antes e depois dos procedimentos, que foram realizados em triplicata.

$\mathrm{O}$ resíduo submetido à temperatura de $1100{ }^{\circ} \mathrm{C}$ foi pulverizado e reutilizado no processo de preparação da pasta de gesso substituindo o gesso puro comercial. Avaliou-se o tempo de cura e a variação de temperatura do processo.

\section{Teste de lixiviação do gesso comercial e do resíduo}

Para avaliar o processo de lixiviação do resíduo e do gesso comercial foram preparados frascos com soluções aquosas em pH 5, em pH 8 e em água destilada, em duplicata. $\mathrm{O}$ valor de $\mathrm{pH}$ foi ajustado utilizando soluções de $\mathrm{HCl}$ e $\mathrm{NaOH} 0,1 \mathrm{~mol} \mathrm{~L}^{-1}$. Amostras de gesso comercial e resíduo de gesso de construção civil foram pesadas e inseridas nas soluções, deixando-as em repouso por 40 dias.

Previamente e ao final dos 40 dias foram determinados nas soluções os parâmetros de: condutividade, por meio de um condutivímetro marca LUTRON CD-4303 calibrado com solução padrão $\mathrm{KCl} 146,9 \mu \mathrm{S} \mathrm{cm}^{-1}( \pm 0,5 \%)$ e exatidão de $2 \%$ do fundo de escala; $\mathrm{pH}$, por meio de um $\mathrm{pHmetro}$ marca LABMETER PHS-3B com resolução de \pm
0,01 e eletrodo de vidro combinado, calibrandose com soluções tampão $\mathrm{pH} 7,0( \pm 0,05)$ e $\mathrm{pH} 4,0$ $( \pm 0,02)$; turbidez, por meio de turbidímetro digital marca Tecnopon TB1000 calibrado com padrões entre 0,1 e 1000 NTU (Nephelometric Turbidity Units) e resolução entre 0,01 a 1,0 dependendo da faixa de trabalho utilizada; teor de $\mathrm{Ca}$, determinado por titulação complexometrica com EDTA $0,01 \mathrm{~mol} \mathrm{~L}^{-1} \mathrm{e}$ indicador Calcon.

Em seguida, novas amostras e soluções foram preparadas e deixadas em repouso por um período de 120 dias. Os mesmos parâmetros avaliados no teste de 40 dias foram realizados para posterior comparação.

Considerando-se a possibilidade de contaminação de chumbo em gesso (FONTANELLA; MISTURA, 2014), determinou-se a presença de chumbo nas amostras de gesso comercial e no resíduo de gesso por meio de um espectrofotômetro de absorção atômica GBC932plus, modalidade chama acetileno/ ar, com lâmpada de catodo oco Photron de $5 \mathrm{~mA}$, no comprimento de onda de $217 \mathrm{~nm}$ e curva de calibração com padrão SpectroSol.

\section{Resultados e Discussão}

\section{Estudo do tempo de cura do gesso}

O tempo de cura do gesso pelo processo tradicional com água foi de 4,08 minutos, utilizado como padrão para comparação. O tempo de cura obtido com cada aditivo utilizado está disposto na Tabela 1 . 
Tabela 1. Tempo de cura do gesso em cada aditivo

\begin{tabular}{cc}
\hline Aditivo & $\begin{array}{c}\text { Tempo de Cura } \\
(\mathbf{m i n} .)\end{array}$ \\
\hline Sulfato de Potássio & 0,27 \\
Sulfato de Magnésio & 1,00 \\
Sulfato de Cálcio & 2,38 \\
Sulfato de Alumínio & 3,93 \\
Sem aditivo (água) & $\mathbf{4 , 0 8}$ \\
Citrato de Sódio & 5,27 \\
Terra Diatomácea $5 \% \mathrm{~m} / \mathrm{v}$ & 6,35 \\
Terra Diatomácea 2\% m/v & 7,25 \\
Sulfato de Sódio & 7,27 \\
Terra Diatomácea $1 \% \mathrm{~m} / \mathrm{v}$ & 7,53 \\
Ácido Cítrico & 16,55 \\
\hline
\end{tabular}

Fonte: os autores.

É possível constatar que a solução de sulfato de sódio e a terra diatomácea a $1 \%, 2 \%$ e $5 \% \mathrm{~m} / \mathrm{v}$ apresentaram maiores tempos de cura do que a água, aumentando o tempo para o trabalho de manufatura de moldes, propiciando a diminuição do desperdício e menor produção de resíduos. Com a solução de ácido cítrico, o tempo de cura foi bastante elevado, mas provocou o surgimento de bolhas, devido à reação do ácido com o sulfato deixando o material poroso e pouco resistente, o mesmo ocorrendo para o aditivo citrato de sódio. Tempos de cura elevados também prejudicam o processo de manufatura dos moldes diminuindo a quantidade fabricada por período de tempo, prejudicando a produtividade.

As soluções de sulfato de cálcio, sulfato de potássio e sulfato de magnésio apresentaram tempos de cura menores que a água e também obtiveram um produto final pouco resistente e com bolhas em sua estrutura e de difícil manipulação.

Avaliou-se também a variação de temperatura no processo, desde o início da mistura até a formação da pasta. A solução de sulfato de potássio apresentou a maior variação de temperatura $\left(+4,0{ }^{\circ} \mathrm{C}\right)$ seguida pela de sulfato de sódio, sulfato de magnésio e citrato de sódio que apresentaram variação de $+2,0{ }^{\circ} \mathrm{C}$ cada. A solução de sulfato de alumínio apresentou variação de apenas $+1,0^{\circ} \mathrm{C}$, e as demais misturas apresentaram variação inferior a $+1,0{ }^{\circ} \mathrm{C}$, incluindo a preparação com água.

Em relação aos testes de resistência à compressão dos moldes de gessos constatou-se que os gessos modificados com sulfato de sódio, citrato de sódio e Terra Diatomácea a $5 \% \mathrm{~m} / \mathrm{v}$ não apresentaram boa resistência mecânica, pois se deformaram com rachaduras com aplicação de pressão menor que o gesso preparado com água ( $0,1 \mathrm{~atm})$. Já os gessos preparados com terra diatomácea a $1 \% \mathrm{~m} / \mathrm{m}$ e $2 \%$ $\mathrm{m} / \mathrm{m}$ apresentaram resistência semelhante ao gesso preparado com água.

Por meio de um paquímetro da marca DIGIMESS (resolução de $\pm 0,05 \mathrm{~mm}$ ) calculou-se a porcentagem de deformação dos moldes modificados com terra diatomácea e também a diferença do diâmetro antes e depois da compressão. A porcentagem de deformação das peças foi de $6,04 \%$, e a redução do diâmetro foi de $24,08 \%$.

A Figura 2 apresenta o espectro de bandas de transmissão na região do infravermelho característico do gesso comercial e do resíduo.

Figura 2: Espectro na região do infravermelho para amostras de gesso comercial e resíduo da construção civil.

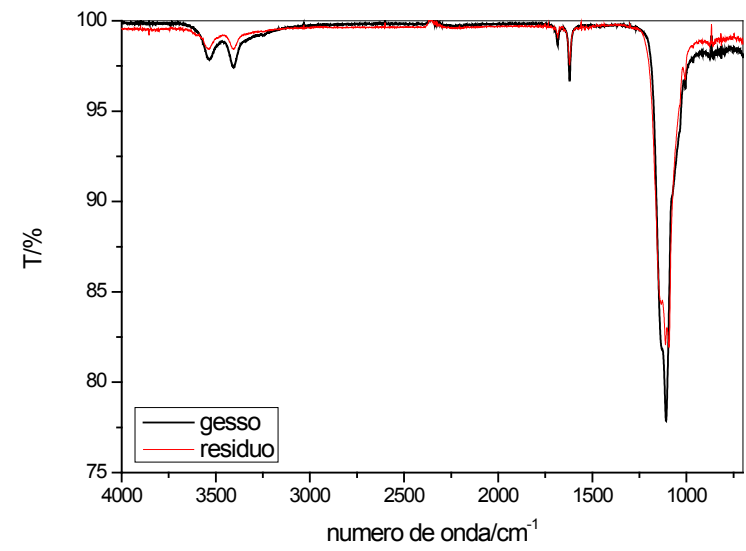

Fonte: os autores. 
A banda em $1120 \mathrm{~cm}^{-1}$ refere-se à deformação do $\mathrm{SO}_{4}^{2-;}$ a banda em $1120 \mathrm{~cm}^{-1}$ pode também indicar a presença de sílica no material devido ao estiramento Si-O-Si; as bandas em 1617 e $1685 \mathrm{~cm}^{-1}$ referem-se à deformação de $\mathrm{OH}$ no plano e indicam a presença de mistura hemidrato e gipsita e as bandas duplas em 3532 e 3406 indicam estiramento $\mathrm{OH}$ característico da gipsita (CARVALHO; LELES; TUBINO, 2008). Nota-se que há apenas diferenças nas intensidades das bandas entre o gesso comercial e o resíduo.

A inclusão de aditivos não provoca deslocamento nas bandas, com pequenas alterações na intensidade. No caso da terra diatomácea, há um alargamento na banda em $1120 \mathrm{~cm}^{-1}$ devido à deformação Si-O-Si da sílica neste aditivo.

Em relação ao aspecto visual dos gessos modificados, observou-se que os gessos preparados com Terra Diatomácea $1 \%, 2 \%$ e $5 \%$ apresentaram melhor aspecto do que os demais aditivos, inclusive considerando o preparado com água. Os demais aditivos não apresentaram resultados significativos que os diferiam em nenhum dos testes.

\section{Estudo do resíduo do gesso}

De acordo com a literatura, o gesso de construção puro possui composição idêntica à do mineral que o originou, a gipsita. Sendo assim, deve possuir em sua estrutura águas de hidratação.

Por meio de cálculos estequiométricos verificou-se que o tratamento térmico à temperatura de $150-200{ }^{\circ} \mathrm{C}$ provoca a perda de 1,5 moléculas de água de hidratação por unidade de $\mathrm{CaSO}_{4}$ contidas no resíduo do gesso, gerando o hemidrato, resultado concordante com Nita et al. (2004). Em temperatura de $1100{ }^{\circ} \mathrm{C}$ ocorre a perda de 2,02 moléculas de água de hidratação por unidade de $\mathrm{CaSO}_{4}$. Após o tratamento térmico a 1100 ${ }^{\circ} \mathrm{C}$, o resíduo gerado consiste em óxido de cálcio $(\mathrm{CaO})$ que pode ser hidratado formando $\mathrm{Ca}(\mathrm{OH})_{2}$ utilizado na construção civil. Contudo, em ambos os tratamentos, é preciso calcular o custo energético dos processos, o que pode inviabilizar a reciclagem devido ao baixo custo do gesso comercial.

\section{Teste de Lixiviação}

Por meio dos testes de lixiviação buscou-se compreender as características do gesso puro e do resíduo mediante diferentes valores de $\mathrm{pH}$ para proporcionar alternativas de descarte do mesmo que minimizem os danos ambientais ao ambiente e possam servir de guia no uso em pisciculturas.

Por meio da avaliação de $\mathrm{pH}$, ao fim do período de lixiviação (40 e 120 dias), foi observado que o pH de todas as soluções encontrava-se na faixa do neutro ao básico, como pode ser visto na Tabela 2.

Considerando a possível aplicação do gesso em piscicultura, este mantém o $\mathrm{pH}$ na faixa recomendada de 6,5 a 9,5 .

Tabela 2: Valores de $\mathrm{pH}$ obtidos nos testes de lixiviação.

\begin{tabular}{ccccc} 
Solução & \multicolumn{2}{c}{${\text { Lixiviação } \mathbf{1}^{\mathbf{a}}}^{\mathbf{2}}$ Lixiviação $2^{\mathbf{b}}$} \\
& $\begin{array}{c}\mathbf{p H} \\
\text { Inicial }\end{array}$ & $\begin{array}{c}\mathbf{p H} \\
\text { Final }\end{array}$ & $\begin{array}{c}\mathbf{p H} \\
\text { Inicial }\end{array}$ & $\begin{array}{c}\mathbf{p H} \\
\text { Final }\end{array}$ \\
\hline $\begin{array}{c}\text { Resíduo/ } \\
\text { Água }\end{array}$ & 6,00 & 7,88 & 6,15 & 7,67 \\
$\begin{array}{c}\text { Resíduo/ } \\
\text { Ácido }\end{array}$ & 5,17 & 8,19 & 5,07 & 7,87 \\
$\begin{array}{c}\text { Resíduo/ } \\
\text { Base }\end{array}$ & 8,10 & 7,81 & 8,54 & 7,89 \\
$\begin{array}{c}\text { Gesso/ } \\
\text { Água }\end{array}$ & 6,00 & 7,67 & 6,69 & 7,69 \\
$\begin{array}{c}\text { Gesso/ } \\
\text { Ácido }\end{array}$ & 5,17 & 7,49 & 5,52 & 7,64 \\
$\begin{array}{c}\text { Gesso/ } \\
\text { Base }\end{array}$ & 8,10 & 7,80 & 8,70 & 7,70 \\
\hline
\end{tabular}

a. 40 dias; b. 120 dias. Erro de $\pm 0,01$, com desvio padrão relativo entre 0,11 e $0,19 \%$.

Fonte: os autores. 
$\mathrm{O}$ aumento do $\mathrm{pH}$ no meio deve-se à liberação de íons hidróxidos para o meio aquoso. Este efeito alcalinizante do gesso é uma das justificativas para seu uso em pisciculturas (PARANÁ, 2001). Percebese também um efeito de tamponamento do meio em relação ao uso de gesso em ambientes já alcalinos, havendo neste caso uma pequena diminuição do $\mathrm{pH}$.

Este efeito deve-se ao fato do íon sulfato ser um ânion básico e a reação de hidrólise gerar íons hidroxila, de acordo com a reação 2 .

$$
\mathrm{SO}_{4}{ }^{2-}(\mathrm{aq})+\mathrm{H}_{2} \mathrm{O}(\mathrm{l}) \leftrightarrows \mathrm{HSO}_{4}^{-}(\mathrm{aq})+\mathrm{OH}^{-}(\mathrm{aq})
$$

Em meio ácido, o efeito pode ser explicado pela reação 3, pois a espécie $\mathrm{HSO}_{4}{ }_{4}^{-}$tem caráter ácido menor que o íon $\mathrm{H}_{3} \mathrm{O}^{+}$.

$$
\mathrm{SO}_{4}^{2-}(\mathrm{aq})+\mathrm{H}_{3} \mathrm{O}^{+}(\mathrm{aq}) \leftrightarrows \mathrm{HSO}_{4}^{-}(\mathrm{aq})+\mathrm{H}_{2} \mathrm{O} \text { (l) (3) }
$$

$\mathrm{O} \mathrm{Ca}^{2+}$ provoca alterações mais sutis no processo, pois tem parâmetro eletrostático $(\zeta)$ calculado em 0,038 , indicando pouca tendência à hidrólise quando comparado a íons facilmente hidrolisáveis, como $\mathrm{Al}^{3+}$ $(\zeta=0,176)$ e $\mathrm{Sn}^{4+}(\zeta=0,216)$.

Os resultados das medidas de condutividade obtidos estão dispostos na Tabela 3.

\begin{tabular}{|c|c|c|c|c|}
\hline \multirow{3}{*}{ Solução } & \multicolumn{2}{|c|}{ Lixiviação $1^{a}$} & \multicolumn{2}{|c|}{ Lixiviação $2^{b}$} \\
\hline & \multicolumn{4}{|c|}{ Condutividade $\left(\mathrm{mS} \mathrm{cm}^{-1}\right)$} \\
\hline & Inicial & Final & Inicial & Final \\
\hline $\begin{array}{c}\text { Resíduo/ } \\
\text { Água }\end{array}$ & 1,09 & 2,16 & 1,80 & 1,99 \\
\hline $\begin{array}{l}\text { Resíduo/ } \\
\text { Ácido }\end{array}$ & 194,1 & 2,19 & 18,60 & 1,69 \\
\hline $\begin{array}{c}\text { Resíduo/ } \\
\text { Base }\end{array}$ & 66,61 & 2,05 & 0,50 & 1,83 \\
\hline Gesso/Água & 1,09 & 1,19 & 3,33 & 1,98 \\
\hline $\begin{array}{l}\text { Gesso/ } \\
\text { Ácido }\end{array}$ & 194,1 & 2,18 & 4,14 & 1,97 \\
\hline Gesso/Base & 66,61 & 1,86 & 4,40 & 2,00 \\
\hline
\end{tabular}

Tabela 3: Valores de condutividade nos testes de Lixiviação.

a. 40 dias; b. 120 dias. Erro de $0,5 \%$

A diminuição na condutividade deve-se ao equilíbrio ácido-base entre os componentes da solução e o material, formando espécies neutras. Isto pode indicar também a precipitação de espécies em solução tornando-as indisponíveis para outras reações químicas.

Os resultados das medidas de turbidez obtidos estão dispostos na Tabela 4. O valor inicial da solução aquosa sem o gesso e o resíduo foi determinado como 0,0 NTU. 
Tabela 4: Valores de turbidez obtidos nos testes.

\begin{tabular}{ccc}
\hline Solução & $\begin{array}{c}\text { Lixiviação 1 }^{\text {a }} \\
\text { Turbidez } \\
\text { (NTU) }\end{array}$ & $\begin{array}{c}\text { Lixiviação 2 }^{\text {b }} \\
\text { Turbidez } \\
\text { (NTU) }\end{array}$ \\
\hline $\begin{array}{c}\text { Resíduo/ } \\
\text { Água } \\
\text { Resíduo/ } \\
\text { Ácido } \\
\text { Resíduo/ } \\
\text { Base }\end{array}$ & 40 & 10,5 \\
$\begin{array}{c}\text { Gesso/Água } \\
\text { Gesso/ } \\
\text { Ácido }\end{array}$ & 0,49 & 10,1 \\
Gesso/Base & 0,31 & 693 \\
\hline
\end{tabular}

a. 40 dias; b. 120 dias. Erro de $\pm 0,01$ para a menor faixa e erro de \pm 10 para a maior faixa.

Fonte: os autores.

De acordo com a resolução do CONAMA 2005-Sessão 2, as águas pertencentes à classe 2 podem apresentar turbidez de até 100 NTU (BRASIL, 2005). Por meio dos resultados obtidos, pode-se observar que, nas amostras de gesso, houve aumento na turbidez para valores acima de 100 NTU no período de 120 dias, mesmo com o pH do meio variando de ácido a básico. Isto é causado pelo menor tamanho das partículas do gesso que se dispersam com mais facilidade no meio aquoso.

Portanto, a destinação correta do gesso possui grande importância, pois em contato com a água de consumo acarretará problemas ambientais, o aumento da turbidez pode afetar a passagem da luz no meio aquático afetando processos fotossintéticos.

A diminuição da turbidez observada para as amostras de resíduos entre o período de 40 e 120 dias pode indicar um processo de reprecipitação do sulfato de cálcio, uma vez que não houve agitação ou movimentação no sistema, que dificilmente ocorre no meio ambiente.

As concentrações de $\mathrm{Ca}^{2+}$ no lixiviado estão dispostas na Tabela 5 .

Tabela 5: Concentração de cálcio das soluções lixiviadas

\begin{tabular}{|c|c|c|}
\hline Solução & 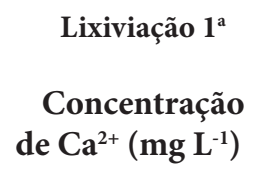 & 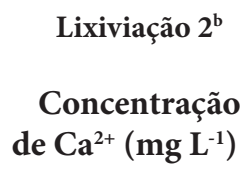 \\
\hline $\begin{array}{c}\text { Resíduo/ } \\
\text { Água }\end{array}$ & 2454,8 & 2244,0 \\
\hline $\begin{array}{c}\text { Resíduo/ } \\
\text { Ácido }\end{array}$ & 2271,2 & 2131,1 \\
\hline $\begin{array}{c}\text { Resíduo/ } \\
\text { Base }\end{array}$ & 2767,6 & 1894,5 \\
\hline $\begin{array}{l}\text { Gesso/ } \\
\text { Água }\end{array}$ & 2142,0 & 2193,7 \\
\hline $\begin{array}{l}\text { Gesso/ } \\
\text { Ácido }\end{array}$ & 2182,8 & 1872,7 \\
\hline $\begin{array}{l}\text { Gesso/ } \\
\text { Base }\end{array}$ & 2223,6 & 2607,1 \\
\hline
\end{tabular}

a. 40 dias; b. 120 dias.

Fonte: os autores.

A liberação do íon $\mathrm{Ca}^{2+} \mathrm{e}$, estequiometricamente, de $\mathrm{SO}_{4}{ }^{2-}$, no meio é significativa, devido à lixiviação dos cristais formados no gesso e no resíduo, ressaltando que o gesso tem em média $66,32 \%$ em massa de Ca. Juntos, Ca e S correspondem a 96,25\% em massa do gesso (BARBOSA; FERRAZ; SANTOS, 2014).

Aplicou-se o teste estatístico de hipótese $\mathrm{t}$ de Student nos resultados obtidos para verificar se há diferenças significativas na concentração de cálcio com o pH. Para isso, calculou-se a média de concentração de cálcio nos diferentes $\mathrm{pH}$ tanto para o resíduo como para o gesso puro, para ambas as lixiviações, em triplicata (Tabela 6). 
Tabela 6: Valores estatísticos utilizados na aplicação do teste $t$ na concentração de Cálcio

\begin{tabular}{|c|c|c|c|c|}
\hline & \multicolumn{2}{|c|}{ Lixiviação $1^{\mathrm{a}}$} & \multicolumn{2}{|c|}{ Lixiviação $2^{\mathrm{b}}$} \\
\hline & Gesso & Resíduo & Gesso & Resíduo \\
\hline $\begin{array}{l}\text { Média } \\
\left(\mathrm{mg} \mathrm{L}^{-1}\right)\end{array}$ & 2183 & 2498 & 2224 & 2090 \\
\hline $\begin{array}{l}\text { Desvio } \\
\text { Padrão }\end{array}$ & 40,8 & 251,0 & 368,2 & 178,8 \\
\hline $\begin{array}{c}\text { Desvio } \\
\text { padrão } \\
\text { relativo } \\
(\%)\end{array}$ & 1,9 & 10,0 & 16,55 & 8,5 \\
\hline
\end{tabular}

a. 40 dias; b. 120 dias.

Fonte: os autores.

Utilizando a equação 1 calculou-se o intervalo $\mu \mathrm{e}$ com a equação 2 calculou-se o valor experimental de $t$.

$$
\begin{array}{ll}
\mu=X \pm \frac{t s}{\sqrt{n}} & \text { Equação 1 } \\
t=\frac{X d \sqrt{n}}{s_{d}} & \text { Equação 2 }
\end{array}
$$

Os valores obtidos encontram-se na Tabela 7.

Tabela 7: Valores obtidos utilizando o teste t de Student.

\begin{tabular}{ccc}
\hline & $\begin{array}{c}\text { Lixiviação 1 }^{\text {a }} \\
\text { Intervalo de } \\
\text { confiança }\end{array}$ & $\begin{array}{c}\text { Lixiviação 2 }^{\text {b }} \\
\text { Intervalo de } \\
\text { confiança }\end{array}$ \\
\hline Gesso & $2182,8 \pm 68,78$ & $2224,5 \pm 620,68$ \\
& $2497,9 \pm 423,35$ & $2089,9 \pm 300,71$ \\
\hline
\end{tabular}

a. 40 dias; b. 120 dias.

Fonte: os autores.

O valor de t calculado para o resíduo foi de 1,427 e para o gesso foi de 2,016. O valor de t crítico com $95 \%$ de confiança é de 4,303. Como o valor de t experimental em todos os casos é menor do que o valor crítico, não há diferença estatisticamente significativa entre os tratamentos em diferentes $\mathrm{pH}$ para o gesso comercial e para o resíduo, indicando que o coeficiente de variação encontrado pode ser atribuído a erros aleatórios, não necessariamente depende do $\mathrm{pH}$.

As concentrações de chumbo encontradas no gesso comercial e no resíduo foram de $4,88 \mathrm{mg} \mathrm{kg}^{-1}$ e $3,88 \mathrm{mg} \mathrm{kg}^{-1}$, respectivamente, valor abaixo do encontrado por Fontanella e Mistura (2014), com $48,28 \mathrm{mg} \mathrm{kg}^{-1}$. De acordo com as Resoluções Conama $n^{\circ} 357 / 2005$ e $n^{\circ} 430 / 2011$ (BRASIL, 2005; BRASIL, 2011), o teor máximo admitido de chumbo em águas e efluentes é de $0,5 \mathrm{mg} \mathrm{L}^{-1}$. Para exceder este teor, seria necessária uma quantidade grande de resíduos de gesso aplicados no tanque. Contudo, é importante ressaltar as características acumulativas do chumbo, principalmente no sedimento que, em longo prazo, pode ocasionar contaminação. Estudos temporais e espaciais de possível contaminação em tanques de piscicultura devem ser realizados em longo prazo.

\section{Conclusões}

Em relação ao aumento do tempo de cura e melhoria no aspecto visual do produto final, o uso de terra diatomácea adicionada em gesso apresentou-se como um aditivo viável e de baixo custo, principalmente se obtido a partir de resíduos de filtros de cervejaria.

Por meio dos testes de lixiviação realizados, constatou-se que a utilização de gesso ou seu resíduo pode alterar características físico-químicas do meio aquoso sendo extremamente importante estudos em pisciculturas nas quais estes resíduos estejam sendo utilizados.

\section{Referências}

ASSOCIAÇÃO BRASILEIRA DE DRYWALL ABD. Resíduos de gesso na construção civil: coleta, armazenagem e reciclagem. São Paulo, 2009.

AVELAR, T. C. Otimização da produção de pré- 
moldados de gesso de alta resistência a partir de gesso de baixo desempenho mecânico. 2012. Dissertação (Mestrado em Desenvolvimento em Processos Ambientais) - Universidade Católica de Pernambuco, Recife.

BADENS, E. Crystallization of gypsum from hemihydrate in presence of additives. Journal of Crystal Growth, v. 198, n. 199, p. 704-709, 1999.

BALTAR, C. A. M. Rochas e minerais industriais. Rio de Janeiro: Centro de Tecnologia Mineral, Ministério da Ciência e Tecnologia, 2005. Cap.21, p. 449-470.

BARBOSA, A. A.; FERRAZ, A. V.; SANTOS, G. A. Caracterização química, mecânica e morfológica do gesso $\beta$ do pólo de Araripe. Cerâmica, v. 60, p. 501508, 2014.

BOYD, C. E. Aluminum Sulfate (alum) for precipitating clay turbidity from fish ponds. Transactions of the American Fisheries Society, v. 108, n. 3, p. 307-313, 1979.

BRASIL. Associação Brasileira de Normas Técnicas - ABNT. NBR 12127: Gesso para construção: Determinação das propriedades físicas do pó. São Paulo, 1991a.

. NBR 12128: Gesso para construção: Determinação das propriedades físicas da pasta. São Paulo, 1991b.

- NBR 12129: Gesso para construção: Determinação das propriedades mecânicas. São Paulo, 1991c.

. NBR 13207: Gesso para construção civil Especificação. São Paulo, 1994.
NBR 10005: Procedimento para obtenção de extrato lixiviado de resíduos sólidos. São Paulo, 2004a.

. NBR 10006: Procedimento para obtenção de extrato solubilizado de resíduos sólidos. São Paulo, 2004b.

- Conselho Nacional de Meio Ambiente CONAMA, Resolução $N^{\circ} 431$, de 24 de maio de 2011. Altera o artigo $3^{\circ}$ da Resolução ${ }^{\circ} 307$, de 5 de julho de 2002, do Conselho Nacional do Meio Ambiente CONAMA, estabelecendo nova classificação para o gesso.

CONAMA. Resolução $N^{\circ} 357$, de 17 de março de 2005 - Publicada no DOU no 053, de 18/03/2005. p. 58-63.

CONAMA. Resolução $N^{o} 430$, de 13 de maio de 2011-Publicada no DOU no 92, de 16/05/2005. p. 89.

CALVO, J. P. Y. Curso internacional de técnico especialista em rocas y minerales industriales. Madrid: Ilustre Colégio Oficial de Geólogos, 2003. p. 16.

CARVALHO, M. T. M.; LELES, M. I. G; TUBINO, R. M. C. TG and DSC studies on plaster residues as recycled material. Journal of Thermal Analysis and Calorimetry, v. 91, p. 621-625, 2008.

FONTANELLA, R.; MISTURA, C. M. Avaliação do uso de resíduos de gesso como condicionador de solo na agricultura. In: CONGRESSO BRASILEIRO DE QUÍMICA, 54., Natal, 2014. Anais... Natal/RN, 2014. GOMES, L. C.; ARAUJO C. A. R. M.; CHIPPARI A. R.; ROUBACH, R. Transportation of juvenile Tambaqui (Colossoma macropomum) in a closed 
system. Braz. J. Biol., v. 66, n. 2A, p. 493-502, 2006.

JOHN, V. M.; CINCOTTO, M. A. Alternativas da gestão de resíduos de gesso: contribuição para reformulação da Resolução CONAMA 307. São Paulo: EPUSP, julho de 2003.

LIMA, S. Y. V. Influência da adição de substâncias orgânicas no tempo de pega do gesso de construção. 2013. Monografia (em Engenharia Civil) Departamento de Ciências Ambientais e Tecnológicas - Universidade Federal Rural do Semiárido - UFERSA, Mossoró/RN.

MARVIN, E. Gypsum Wallboard Recycling and Reuse Opportunities in the State of Vermont. Vermont: Agency of Natural Resources, 2000.

NITA, C.; PILEGGI, R. G.; CINCOTTO, M. A.; JOHN, V. M. Estudo da reciclagem do gesso de construção. In: CONFERÊNCIA LATINO-AMERICANA DE CONSTRUÇÃO SUSTENTÁVEL, 1. ; ENCONTRO NACIONAL DE TECNOLOGIA DO AMBIENTE CONSTRUÍDO, 10., São Paulo, 2004. Anais... São Paulo/SP, 2004.

PARANÁ. Instituto Paranaense de Assistência Técnica e Extensão Rural - EMATER. Caderno Piscicultura: Modulo II, 2001.

QUEIROZ, J. F.; SILVEIRA, M. P. Recomendações práticas para melhorar a qualidade da água e dos efluentes dos viveiros de Aquicultura. Circular técnica 12. Empresa Brasileira de Pesquisa Agropecuária EMBRAPA Meio Ambiente. 2006.

RIBEIRO, R. C. C.; MACHADO, G. A. Efeito da ação de sais na cinética do processo de cura do gesso. In: CONGRESSO BRASILEIRO DE QUÍMICA, 53., Rio de Janeiro, 2013. Anais... Rio de Janeiro, 2013.
ROWAN, M. Chemical phosphorus removal from aquaculture pond water and effluent. 2001. Thesis (PhD) - Auburn University, Auburn, Alabama. USA.

SÁ N. H. R.; PIMENTEL L. L. Avaliação do desperdício de gesso aplicado como revestimento. In: ENCONTRO DE INICIAÇÃO CIENTÍFICA DA PUC, 14, Campinas, 2009. Anais... Campinas, 2009.

SANTOS, P. M.; ROLIM, M. M.; DUARTE, A. S.; BARROS, M. F. C.; FRANÇA E SILVA, E. F. Uso de resíduos de gesso como corretivo em solo salinosodico. Pesq. Agrop. Trocipal, v. 44, n. 1, p. 95-103, 2014.

SILVEIRA, C. B.; GOULART, M. R.; CAMPOS, M. L.; ALMEIDA, J. A.; COIMBRA, S. M.; OLIVEIRA, A. F. Metodologias para reutilização do resíduo de terra diatomácea, proveniente da filtração e clarificação da cerveja. Química Nova, v. 34, n. 4, p. 625-629, 2011.

Recebido em 18 Março, 2015 - Received on March 18, 2015 Aceito em 15 Março, 2017 - Accepted on March 15, 2017 